\title{
Liquid Chromatography/Tandem Mass Spectrometry for the Simultaneous Determination of Ursodiol and its Major Metabolites, Tauroursodeoxycholic Acid and Glycoursodeoxycholic Acid in Human Plasma
}

\author{
M. GANESAN ${ }^{1 *}$, S. NANJUNDAN ${ }^{1}$, S. VISWANATHAN ${ }^{2}$, AND G. UMA $^{3}$ \\ ${ }^{1}$ Department of Chemistry, Anna University, Chennai-600025, India \\ ${ }^{2}$ Micro Therapeutic Research Labs Private Limited, Chennai-600 059, India \\ ${ }^{3}$ C.LBaid Metha College of Pharmacy, Chennai-600 097, India \\ ganesanmicrotherapsphd@gmail.com
}

Received 15 November 2011; Accepted 15 January 2012

\begin{abstract}
A rapid and sensitive method is described for the quantification of ursodiol and its major metabolites glycoursodeoxycholic acid (GUDCA) and tauroursodeoxycholic acid (TUDCA) in human plasma using single internal standard (Ursodeoxycholic Acid d4). Solid phase extraction was performed and chromatographic separation of $5 \mu \mathrm{L}$ injected sample was achieved using Waters Xterra, $5 \mu \mathrm{m}$ column with a mobile phase comprised of methanol and 5 $\mathrm{mM}$ ammonium formate with $0.1 \%$ acetic acid $(70: 30, \mathrm{v} / \mathrm{v}$ ). The mass spectrometer was used in negative ion mode and multiple reactions monitoring using electro spray ionization mode as an interface. The method was fully validated and the calibration curves were linear over the concentration range of 25.9 to $15300.1 \mathrm{ng} / \mathrm{mL}$ for ursodiol, 2.7 to $1587.5 \mathrm{ng} / \mathrm{mL}$ for tauroursodeoxycholicacid and 25.4 to $15040.9 \mathrm{ng} / \mathrm{mL}$ for glycoursodeoxycholic acid. The method was sensitive and specific, with the lower limit of quantification of 25.9, 2.7 and $25.4 \mathrm{ng} / \mathrm{ml}$ for ursodiol, tauroursodeoxycholic acid and glycoursodeoxycholic acid respectively. The present method includes a simple and rapid sample preparation with shorter analysis run time and less flow rate compared to previously reported methods. The method was applied successfully for a bioequivalence study in healthy subjects.
\end{abstract}

Keywords: Ursodiol, LC-MS/MS, plasma,Validation.

\section{Introduction}

Ursodiol, $3 \alpha, 7 \beta$-dihydroxy-5 $\beta$-cholan-24-oic acid is a naturally occurring bile acid found in small quantities in human plasma. Ursodeoxycholic acid regulates cholesterol by reducing the rate at which the intestine absorbs cholesterol molecules ${ }^{1-3}$. In the liver it is conjugated with glycine or taurine and then secreted into the hepatic bile ducts. These conjugates are 
absorbed in the small intestine. The conjugate is deconjugated in the ileum, leading to formation of free ursodiol. Several analytical methods ${ }^{4-7}$ have been developed for the determination of bile acids in biological fluids. These methods may not be suitable for the processing of multiple samples in a limited period of time for pharmacokinetic studies. In recent years, bioequivalence studies are the commonly accepted method to demonstrate therapeutic equivalence between the medicinal products. A suitable and simple LC-MS/MS method for the simultaneous determination of ursodiol, and its metabolites tauroursodeoxycholic acid (TUDCA) and glycoursodeoxycholic acid (GUDCA) is most important for pharmacokinetic studies ${ }^{8-10}$. Also the measurement of these metabolites in human plasma may be helpful in understanding the metabolism of the parent compound. So, the present study describes a highly sensitive, rapid, reliable liquid chromatography/tandem mass spectrometry (LC-MS/MS) method for the simultaneous quantification of ursodiol, tauroursodeoxycholic acid and glycoursodeoxycholic acid in human plasma using single internal standard Ursodeoxycholic Acid D4.

\section{Experimental}

\section{Chemicals and Reagents}

Methanol, Acetonitrile and Water were HPLC Grade, Ammonium Formate and Formic Acid were AR Grade, $\mathrm{K}_{3}$ EDTA human plasma supplied by Micro therapeutic research labs Pvt Ltd, Ursodiol purchased from Dipharma (Italy), Tauroursodeoxycholic Acid and Glycoursodeoxycholic Acid from TLC Pharma Chem (Canada), Ursodiol-d4 from Varda Biotech (P) Ltd, Mumbai ( India).

\section{Analytical System}

The mass spectroscopic detection was performed on Acquity UPLC with API 4000 triple quadrupole instrument (AB Sciex, USA) equipped using electrospray negative ionization. The chromatography was performed on a Waters Xterra, $5 \mu \mathrm{m}$ column at a temperature of 40 ${ }^{\circ} \mathrm{C}$. The gradient mobile phase composition was a mixture of Methanol and $5 \mathrm{mM}$ ammonium formate with $0.1 \%$ acetic acid (70:30) solution which was pumped at a flow rate of $0.2 \mathrm{~mL} / \mathrm{min}$ with injection volume of $5 \mu \mathrm{L}$. Chromatograms were acquired using the computer based Analyst Software version 1.4.2. supplied by applied bioscience and the data were processed by peak area ratio. The ion spray potential was set at $-4500 \mathrm{kV}$ and the source of temperature was $500^{\circ} \mathrm{C}$. The collision activation dissociation (CAD) gas setting at 12; Nitrogen gas was used as collision gas. The mass spectrometer was used in negative ion mode and multiple reaction monitoring (MRM) using electro spray ionization mode as an interface.

The mass transition ion pair in negative mode was $\mathrm{m} / \mathrm{z} 391.30 \rightarrow 373.2$ for Ursodiol, $\mathrm{m} / \mathrm{z}$ $498.50 \rightarrow 124.0$ for TUDCA, $\mathrm{m} / \mathrm{z} 448.30 \rightarrow 74.0$ for GUDCA and $\mathrm{m} / \mathrm{z} 395.20 \rightarrow 377.20$ for internal standard respectively. The developed method has the advantage of determining Ursodiol, TUDCA and GUDCA simultaneously without any enzymatic conversion of metabolites into parent compound. Figure 1 to 4 shows MS-MS scan for Ursodiol, TUDCA and GUDCA. 


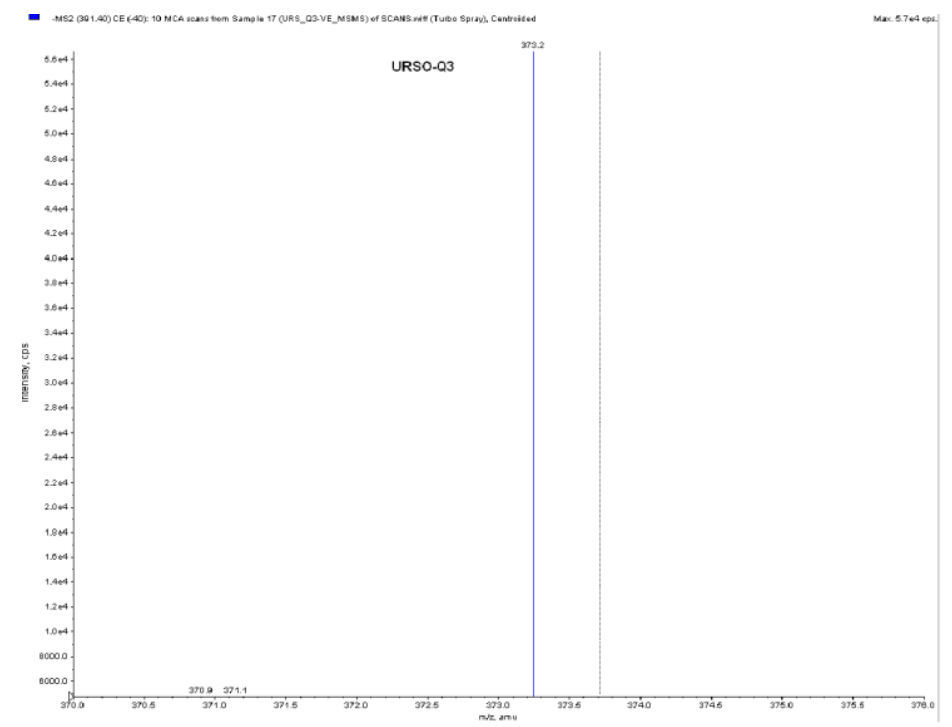

Figure 1. Product ion mass spectra of the $[\mathrm{M}+\mathrm{H}]+$ ions of Ursodiol.

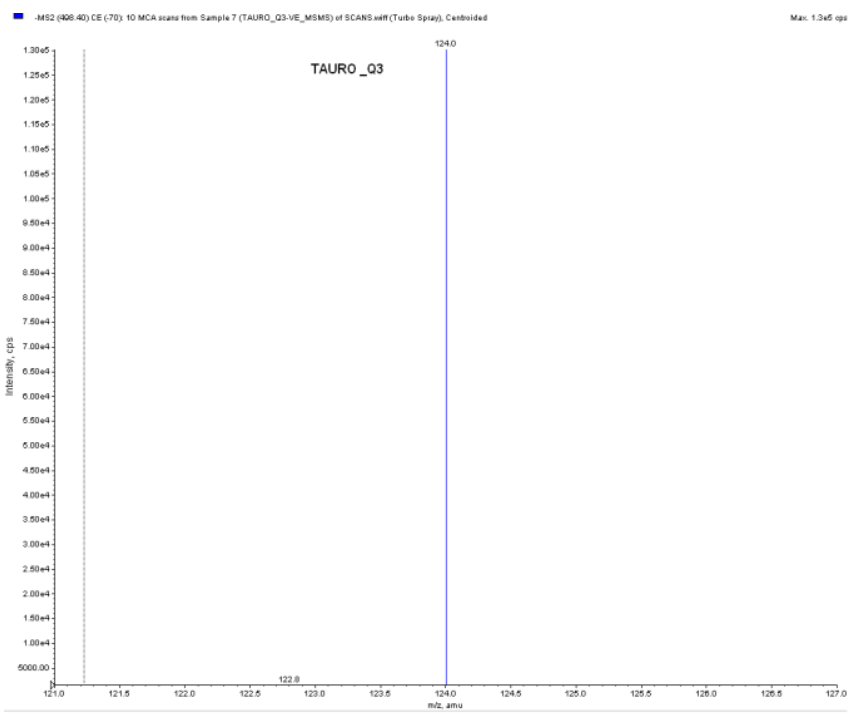

Figure 2. Product ion mass spectra of the $[\mathrm{M}+\mathrm{H}]+$ ions of Tauroursodeoxycholicacid.

\section{Preparation of Calibration Curve (CC) Standards and Quality Control (QC) Samples}

A stock solution of internal standard Ursodiol-d4, Ursodiol, TUDCA and GUDCA with a concentration of $2000 \mu \mathrm{g} / \mathrm{mL}$ were prepared by dissolving the appropriate quantities in methanol and stored at $2^{\circ} \mathrm{C}$ to $8^{\circ} \mathrm{C}$. Working standard solutions were prepared from stock solutions, by dilution with methanol: Water $(50: 50, \mathrm{v} / \mathrm{v})$. Nine-point standard calibration curves were obtained by dissolving appropriate amounts of ursodiol, tauroursodeoxycholic acid and glycoursodeoxycholic acid in plasma samples with the concentrations ranged 
between 25.9 to $15300.1 \mathrm{ng} / \mathrm{mL}$ for ursodiol, 2.7 to $1587.5 \mathrm{ng} / \mathrm{mL}$ for TUDCA and 25.4 to $15040.9 \mathrm{ng} / \mathrm{mL}$ for GUDCA. Calibration curves were constructed by plotting peak height ratio $(y)$ of analyte to the internal standard versus the analyte concentration $(x)$. A linear regression was used for quantitation.

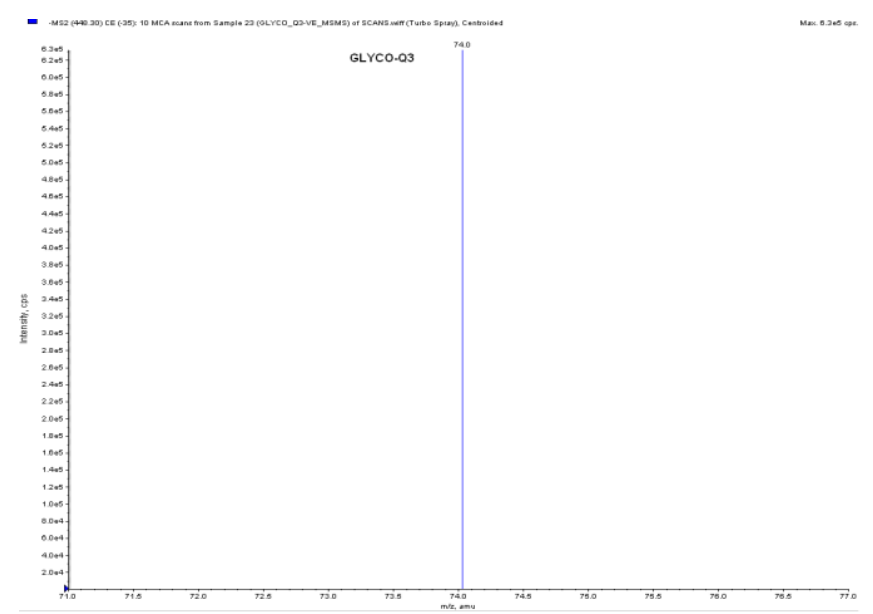

Figure 3. Product ion mass spectra of the $[\mathrm{M}+\mathrm{H}]+$ ions of Glycoursodeoxycholic acid.

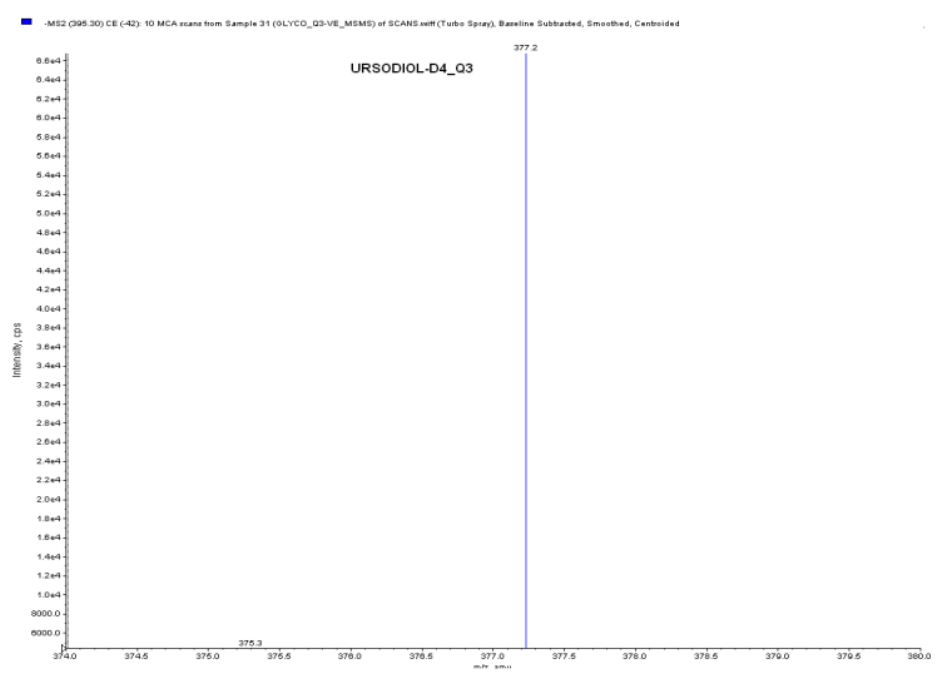

Figure 4. Product ion mass spectra of the $[\mathrm{M}+\mathrm{H}]+$ ions of IS.

\section{Plasma Sample Preparation}

To a $500 \mu \mathrm{L}$ of sample, $50 \mu \mathrm{L}$ of internal standard $\left(20 \mu \mathrm{g} / \mathrm{mL}\right.$ Ursodiol $\left.\mathrm{d}_{4}\right), 400 \mu \mathrm{L}$ of $5 \mathrm{mM}$ ammonium formate solution were added and vortexed. The Strata $\mathrm{X}$ cartridges were conditioned with $1 \mathrm{~mL}$ of methanol followed by $1 \mathrm{~mL}$ of Water. The samples were loaded into cartridges, washed with $1 \mathrm{~mL}$ of water three times and eluted with $1 \mathrm{~mL}$ of methanol 
once. All the samples were dried at $40^{\circ} \mathrm{C}$ and 15 psi, reconstituted and vortexed. The samples were transferred into auto-injector vials and the processed samples were loaded into UPLC-MS/MS.

\section{Validation Procedures}

The objective of validation of an analytical procedure ${ }^{11-13}$ is to demonstrate that it is suitable for its intended purpose (International Conference on Harmonization Guideline Q2A). The specificity of the method was determined by analyzing seven different batches of human plasma samples from seven individual healthy donors receiving no medication were extracted and analyzed for the assessment of potential interference due to endogenous substances. Representative chromatogram illustrating the specificity of the method are shown in Figure 5 to 8 . The linearity of the method was determined by a weighted least square regression analysis of standard plots associated with a nine point standard calibration curve. The calibration line was shown to be linear from 25.88 to $15300.05 \mathrm{ng} / \mathrm{mL}$ for Ursodiol, 2.68 to $1587.48 \mathrm{ng} / \mathrm{mL}$ for Tauroursodeoxycholic acid and 25.44 to 15040.93 $\mathrm{ng} / \mathrm{mL}$ for Glycoursodeoxycholic acid. Assay precision and accuracy (inter-day and intraday) values were determined across three precision and accuracy batches by analyzing six replicates each of LOQQC, LQC, MQC, and HQC samples in each batch. One of the precision and accuracy batch was performed by different analyst to ensure ruggedness of the method. The stabilities were assessed under varying storage and handling conditions and determined by calculating the percentage nominal of LQC and HQC samples against freshly prepared calibration curve standards and compared with bulk spiked comparison samples (CS). As a part of method validation bench-top, in-injector and freeze thaw were also evaluated.

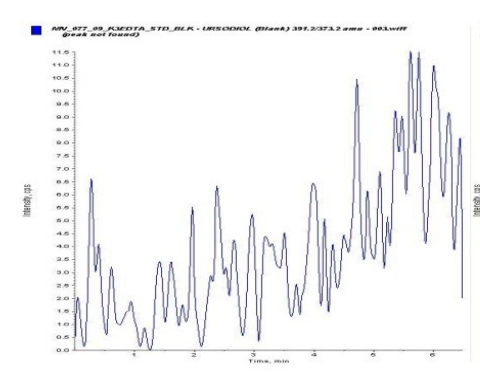

(a)

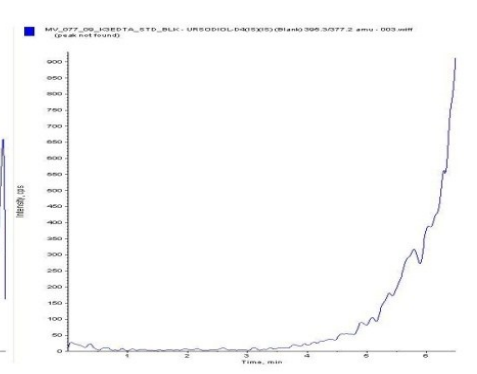

(b)

Figure 5. Representative Chromatogram plasma blank for (a) ursodiol and (b) IS.

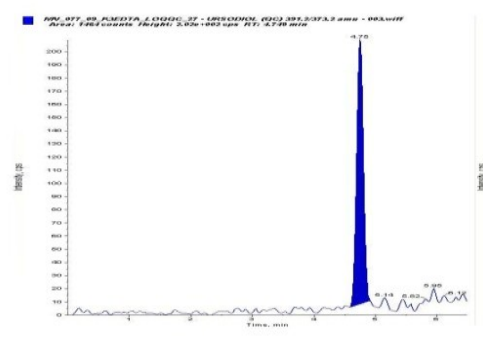

(a)

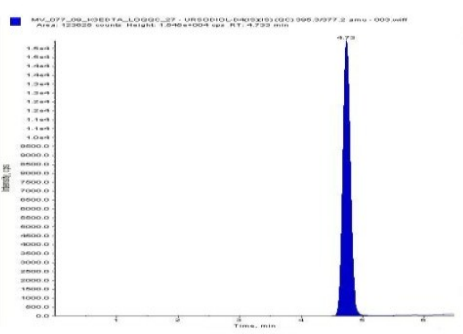

(b)

Figure 6. Representative Chromatogram of LOQQC sample for (a) Ursodiol and (b) IS. 


\section{Results and Discussion}

The assay was found to be linear for Ursodiol concentrations in the range 25.88 to 15300.05 $\mathrm{ng} / \mathrm{mL}, 2.68$ to $1587.48 \mathrm{ng} / \mathrm{mL}$ for Tauroursodeoxycholic acid and 25.44 to $15040.93 \mathrm{ng} / \mathrm{mL}$ for Glycoursodeoxycholic acid. The precision and accuracy were studied satisfactory at five QC concentrations for Ursodiol. The results obtained from precision and accuracy are listed in Table 1, 2, and 3. The average recovery of Ursodiol, Tauroursodeoxycholic acid and Glycoursodeoxycholic acid was 71.26, 69.28, 71.18\%. The percentage CV of the mean recovery of the low, middle and high QC samples of Ursodiol, Tauroursodeoxycholic acid and Glycoursodeoxycholic acid were found to be 5.89, 3.92 and 3.78. The mean recovery of internal standard was $72.98 \%$. The results of the stability studies showed that no significant degradation was observed under the test conditions which indicates that compounds were highly stable in plasma. The values obtained for the stability studies were within the acceptance criteria.

Table 1. Data of Intra day and Inter day accuracy and precision for Ursodiol.

\begin{tabular}{cccccccc}
\hline \multicolumn{3}{c}{ Intra day } & \multicolumn{7}{c}{ Inter day } \\
& $\begin{array}{c}\text { Nominal } \\
\mathrm{ng} / \mathrm{ml}\end{array}$ & Mean & Accuracy, $\%$ & $\begin{array}{c}\mathrm{CV}, \\
\%\end{array}$ & Mean & Accuracy\% & CV,\% \\
\hline LOQQC & 26.21 & 28.52 & 108.81 & 12.33 & 26.03 & 99.33 & 12.85 \\
LQC & 77.09 & 85.49 & 110.89 & 7.25 & 80.81 & 104.82 & 6.95 \\
MIQC & 1101.32 & 1143.98 & 103.87 & 2.45 & 1107.92 & 100.60 & 4.56 \\
MQC & 4405.31 & 4496.10 & 102.06 & 1.08 & 4485.62 & 101.82 & 2.26 \\
HQC & 11412.73 & 11466.53 & 100.47 & 2.19 & 11151.54 & 97.71 & 2.64 \\
\hline $\mathrm{n}=6$ & & & & & & & \\
\hline
\end{tabular}

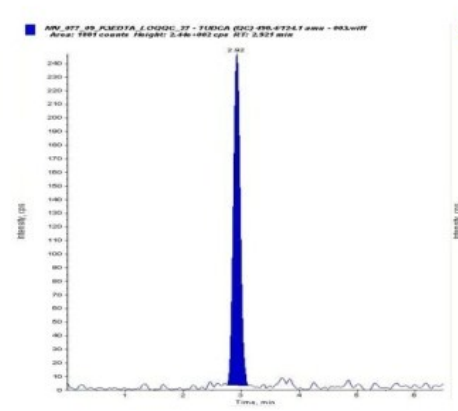

(a)

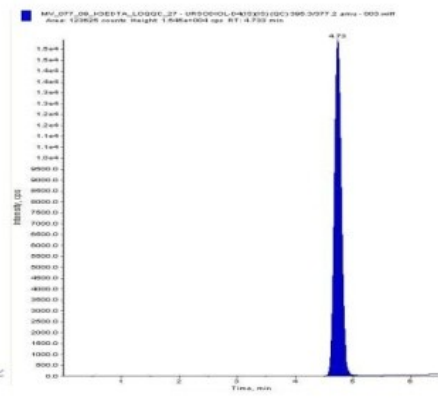

(b)

Figure 7. Representative Chromatogram of LOQQC sample for (a) TUDCA and (b) IS. 


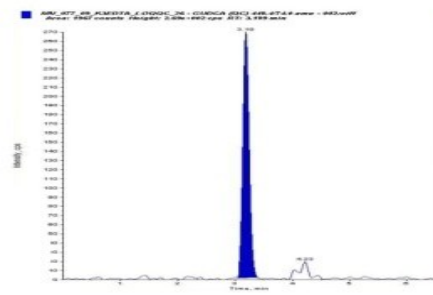

(a)

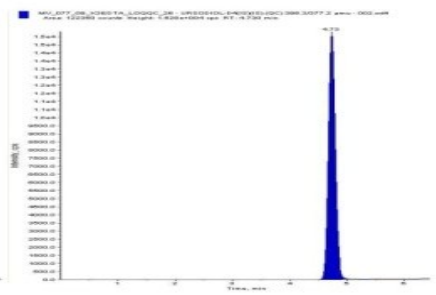

(b)

Figure 8. Representative Chromatogram of LOQQC sample for (a) GUDCA and (b) IS

Table 2. Data of Intra day and Inter day accuracy and precision for TUDCA.

\begin{tabular}{cccccccc}
\hline \multicolumn{3}{c}{ Intra day } & & \multicolumn{3}{c}{ Inter day } \\
& $\begin{array}{c}\text { Nominal } \\
\mathrm{ng} / \mathrm{ml}\end{array}$ & Mean & Accuracy, $\%$ & $\begin{array}{c}\mathrm{CV}, \\
\%\end{array}$ & Mean & Accuracy\% & CV,\% \\
\hline LOQQC & 2.69 & 2.58 & 96.03 & 6.89 & 2.65 & 98.54 & 8.06 \\
LQC & 7.92 & 7.77 & 98.09 & 3.51 & 7.57 & 95.58 & 6.75 \\
M1QC & 113.23 & 104.15 & 91.98 & 3.78 & 103.66 & 91.55 & 4.14 \\
MQC & 452.92 & 410.17 & 90.56 & 5.86 & 431.48 & 95.27 & 5.47 \\
HQC & 1173.38 & 1144.27 & 97.52 & 4.73 & 193.07 & 101.68 & 4.48 \\
\hline $\mathrm{n}=6$ & & & & & \\
\hline
\end{tabular}

Table 3. Data of Intra day and Inter day accuracy and precision for GUDCA.

\begin{tabular}{cccccccc}
\hline \multicolumn{3}{c}{ Intra day } & & \multicolumn{3}{c}{ Inter day } \\
& $\begin{array}{c}\text { Nominal } \\
\mathrm{ng} / \mathrm{ml}\end{array}$ & Mean & Accuracy, $\%$ & $\begin{array}{c}\mathrm{CV}, \\
\%\end{array}$ & Mean & Accuracy\% & CV,\% \\
\hline LOQQC & 25.88 & 26.96 & 104.19 & 8.73 & 25.46 & 98.39 & 11.82 \\
LQC & 76.13 & 76.04 & 99.88 & 6.22 & 72.35 & 95.03 & 7.62 \\
M1QC & 1087.59 & 1088.08 & 100.04 & 1.28 & 1017.01 & 93.51 & 4.91 \\
MQC & 4350.38 & 4284.12 & 98.48 & 2.44 & 4302.52 & 98.90 & 3.32 \\
HQC & 11270.41 & 11665.12 & 103.50 & 3.11 & 11598.78 & 102.91 & 3.24 \\
\hline $\mathrm{n}=6$ & & & & & & \\
\hline
\end{tabular}




\section{Conclusion}

The LC-MS/MS method described for Ursodiol, Tauroursodeoxycholic acid and Glycoursodeoxycholic acid was simple, rapid, reproducible and suitable for their determination in human plasma. These methods also have a good sensitivity, specificity and are also suitable for high throughput clinical sample analysis. There were no significant interferences and matrix effects by endogenous compounds throughout the analysis. These methods can also be used as therapeutic drug monitoring technique to evaluate the pharmacokinetic parameters of drug molecules in human plasma. The developed and validated method has its own advantage and significance which can be applied for successful clinical pharmacokinetic studies.

\section{References}

1. Nobilis M, Pour M, Kunes J, Kopecky J, Kvetina J, Svoboda Z, Sladkova K and Vortel J, J Pharm Biomed Anal., 2001, 24(5/6), 937-946.

2. Lianidou E S, Papastathopoulos D S and Siskos P A, Anal Biochem., 1989, 179(2), 341.

3. Chakravarthy V, Sanduja R, Wong J, McManus K, Likhari P and Hul, BA Research International., 2006, Oct 30 .

4. Swobodnik W, Zhang Y Y, Klueppelberg U, Janowitz P, Wechsler J G, Fuerst P and Ditschuneit H, J Chromatogr B Biomed Sc. Appl., 1987, 423 , 75-84.

5. Tessier E, Neirinck L and Zhu Z, J. Chromatogr., B, 2003, 798 (2), 295-302.

6. Giunchedi P, Scalia S, Maggi L and Conte U, Int. J. Pharm., 1996, 130 (1), 41-47.

7. Raghunadha Reddy S, Sarath Chandran I, Jayaveera K N and Koteswara Rao Divi, $J$ Chem Pharm Res., 2010 , 2(3), 59-69.

8. Alvisi V, Gasparetto A, Dentale A, Heras H, Felletti-Spadazzi A and D'Ambrosi A, Drugs Exp Clin Res., 1996, 22(1), 29-33.

9. Simoni P, Sabatini L, Baraldini M, Mirasoli M, Roda A and Roda E, Int J Clin Pharmacol Res., 2002, 22(2), 37-45.

10. Simoni P, Cerrè C, Cipolla A, Polimeni C, Pistillo A, Ceschel G, Roda E and Roda A, Pharmacol Res., 1995, 31(2), 115-119.

11. The European Agency for the Evaluation of Medicinal Products, Note for Guidance on the Investigation of Bioavailability and Bioequivalence, 2001, http://www.eudra.org/emea.html.

12. U.S. Department of Health and Human Services, Food and Drug Administration, Guidance for Industry-Bioanalytical Method Validation, 2001, http://www.fda.gov/cvm.

13. Guidance for Industry, Bioanalytical Method Validation, US department of Health and Human Services, Food and Drug Administration, May 2001. 


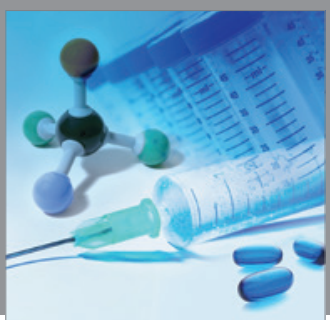

International Journal of

Medicinal Chemistry

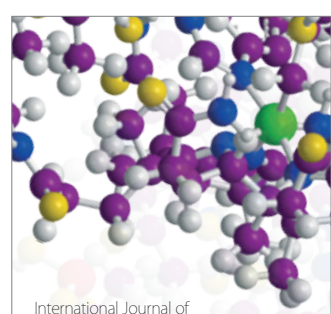

Carbohydrate Chemistry

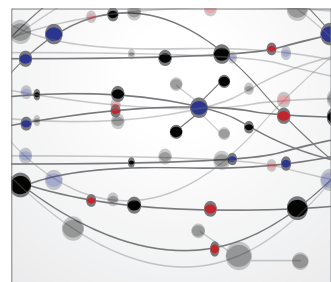

The Scientific World Journal
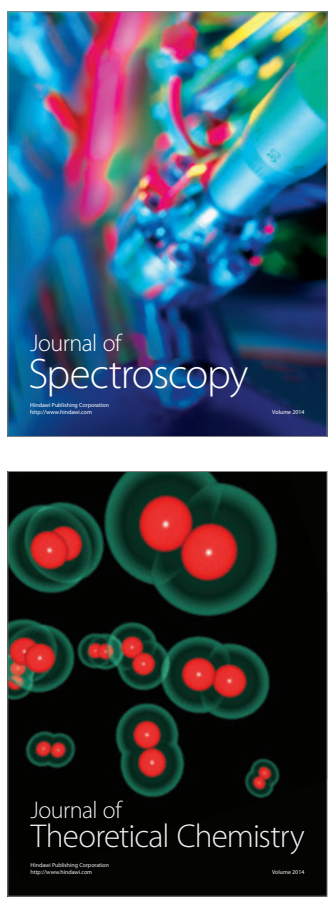
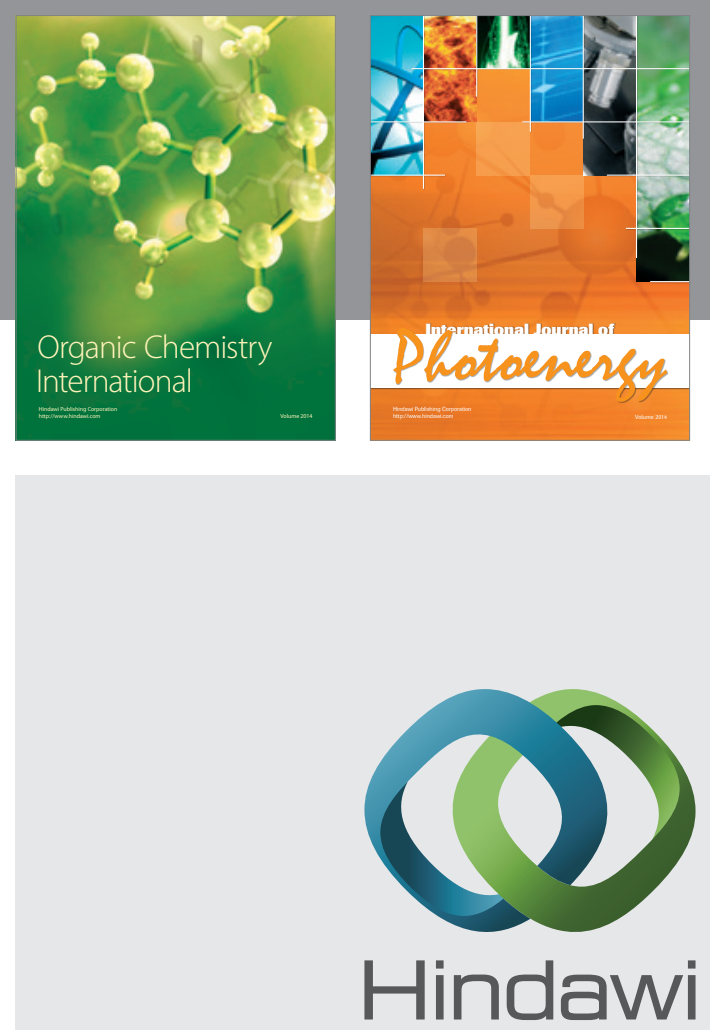

Submit your manuscripts at

http://www.hindawi.com
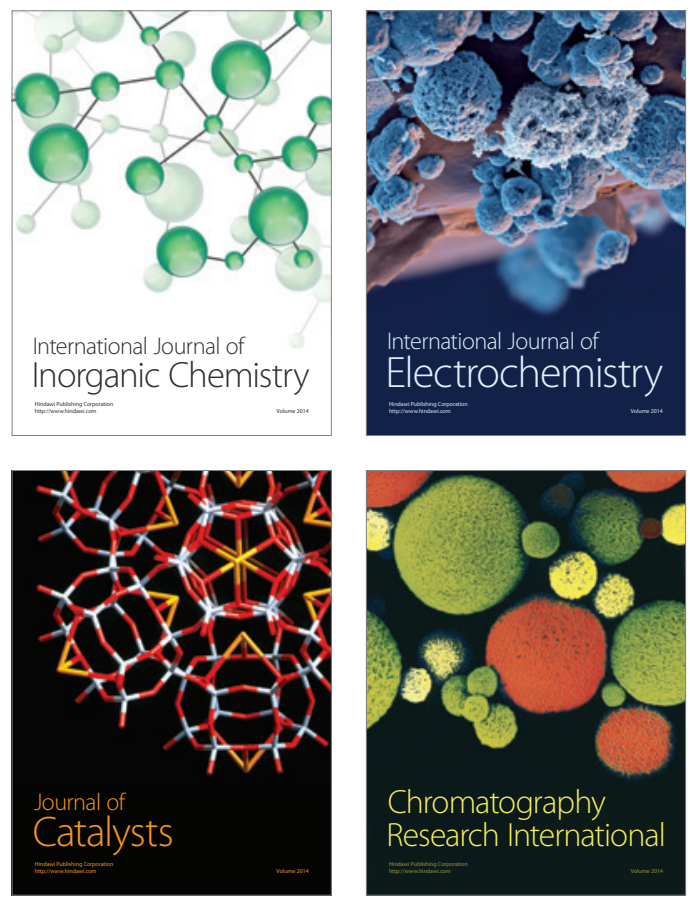
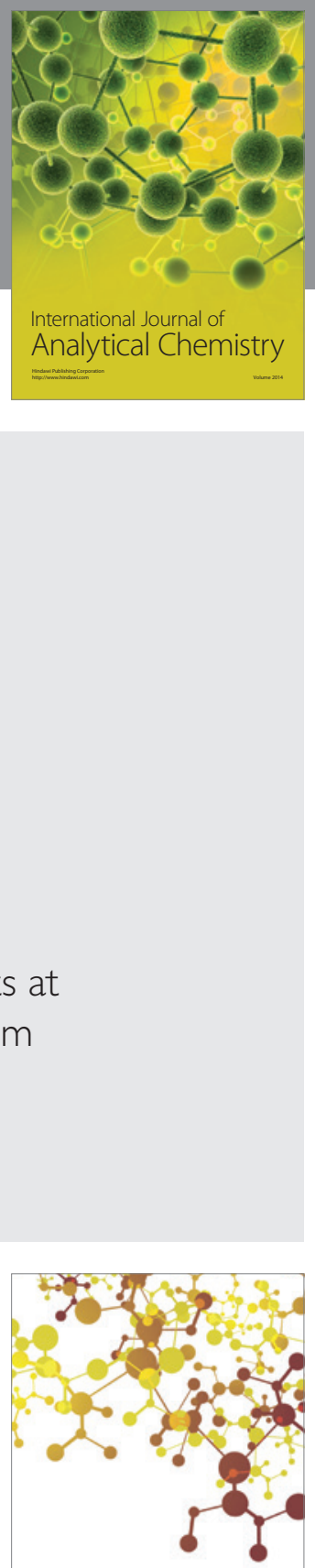

Journal of

Applied Chemistry
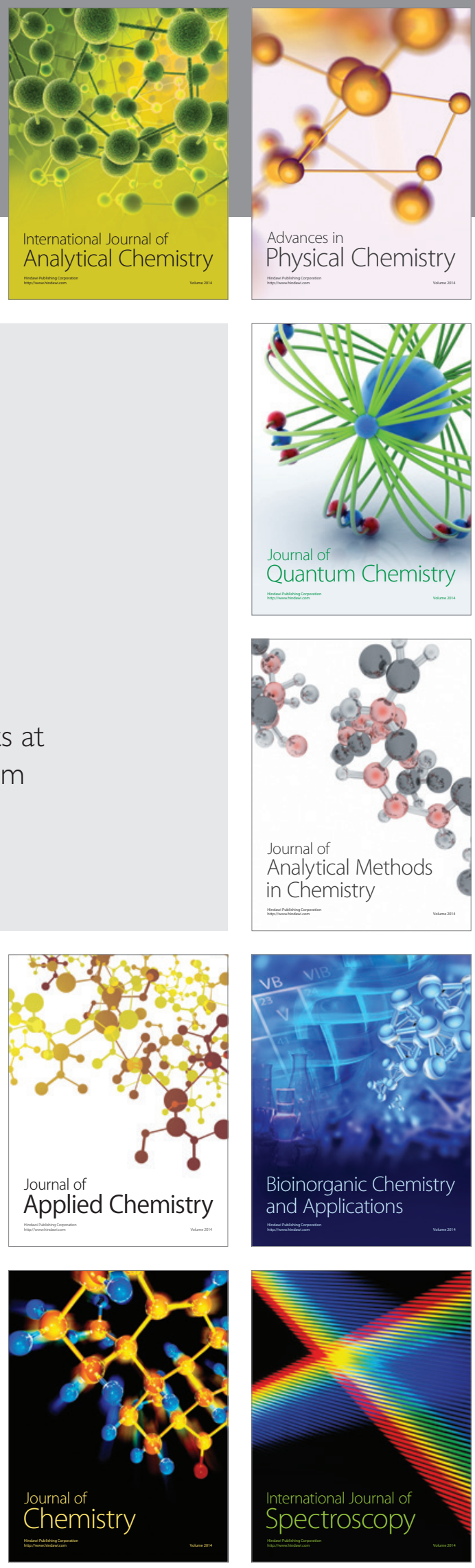